\title{
Theoria cum praxi: la vuelta a la complejidad (Apuntes para una filosofía práctica desde el perspectivismo leibniziano)
}

\author{
CONCHA ROLDÁN \\ Instituto de Filosofia, CSIC
}

\begin{abstract}
A la memoria de Ezequiel de Olaso, maestro y amigo
\end{abstract}

Este trabajo trata de elaborar una hipótesis sobre el papel de Leibniz en la formación de las grandes categorías de la filosofía práctica moderna, poniendo de relieve una idea de racionalidad uhermenéutica» o «imperfecta» que, partiendo del concepto leibniziano de perspectivismo, constaría de tres grandes vertientes que aquí se denominan (de acuerdo con el espíritu de la metodologia de Leibniz) "principios»: de contingencia, autonomia y tolerancia. Lo que a Leibniz le interesa es asegurar una libertad autodeterminista de cuño rigurosamente modemo, subrayando que el universo de la praxis humana está presidido por el factum de lo contingente o de «aquello que puede ser de otra manera". Desde su concepto de individuación no se enfatiza la autonomía racional de un yo desencarnado ni mucho menos de un «autómata previsible», sino la consciencia de una subjetividad autodiferenciada que se propone a sí misma hipótesis viables para salvar la coherencia de sus acciones. El espiritu de tolerancia constituye la conclusión ética de las dos premisas anteriores: la idea general de justicia sólo es asequible desde el peculiar punto de vista de la place d'autruy, que viene a constituir el fundamento de aquélla.

\section{PLANTEAMIENTO}

Si tuviéramos que situar en el tiempo el inicio de la Modernidad, lo hariamos coincidir sin duda con el período en que se declaró la denominada «disputa entre antiguos y modernos». La conciencia de iniciar una nueva época se debía en gran parte al cambio de paradigma científico experimentado, aunque tampoco hay que desdeñar la influencia de los cambios sociales, políticos y religiosos en esta discusión acerca de la superioridad de la filosofía moderna. Algunos pensadores, como Bacon, propugnaron una ruptura radical con el pasado y un nuevo comienzo, en el que, naturalmente, sus obras tenían un especial 
protagonismo'. Otros, como Fontenelle, a pesar de inclinar la balanza por la superioridad de «lo nuevo», reconocieron su deuda con el pasado ${ }^{2}$. Pero quizá la creencia común por todos compartida fue la capacidad de la razón humana para confeccionar discursos totalizadores y sistemáticos que explicaran la realidad en su conjunto.

El debate de las últimas décadas entrc Modernos y Posmodernos no ha discurrido precisamente por cauces muy diferentes en lo que a la tensión ruptura-continuidad se refiere. Ahora bien, aunque tanto los partidarios de la modcrnidad como de la posmodernidad compartirían probablemente la creencia en la quiebra de una racionalidad absoluta que construye discursos globalizadores, la actitud ante los clásicos que ambos mantienen no deja de ser diferente. Se trata en definitiva de optar por subrayar el «cambio radical» o la «herencia anterior», de poner el acento en la perspectiva de la continuidad o la discontinuidad de la historia de las ideas, del lenguaje filosófico.

Desde mi punto de vista, un balance crítico del conjunto de las pretensiones de la Modernidad no puede conducir a renunciar a todas y cada una de sus conquistas. En csto me declaro entusiasta seguidora de la Begriffsgeschichte, que quiere definir las ideas clave de nuestro arsenal moral y político (cosas tales como la libertad o el progreso, la legitimidad o la soberanía, la autonomía o la autodeterminación) en virtud de un doble componente: de un lado, lo que tienen de radicalmente innovador - de exponente de una experiencia especificamente moderna - dc otro, lo que conservan, a la manera de un palimpsesto o pentimento, de modos de pensar y de ordenar el mundo distintos y anteriores a la emergencia del novum de la Modernidad; esto es, con palabras de Koselleck, cuando un novedoso Erwartungshorizont u horizonte de cxpectativas se emancipa del Erfahrangsraum o espacio habitual de experiencia.

De acuerdo con esta teoría, en la construcción del novum de nuestra racionalidad posmoderna se traslucirían retazos de la conceptualización pasada, aunque sólo fuera como restos de un lenguaje genuinamente Moderno que han de ser reinterpretados. En esto se cifra precisamente el trabajo del filósofo como historiador de las ideas, en descubrir e interpretar esos elementos del pasado que emergen en nuestro cuadro o panorama contemporáneo.

Pero además, no puede desdeñarse la virtualidad renovadora de las concepciones clásicas, que puede infundir nuevas fuerzas a nuestra creatividad, al descubrir planteamientos que en un momento dado quedaron en la sombra y que, paradójicamente, en otro momento contribuyen a arrojar luz sobre una determinada problemática, $o$, precisamente, al adoptar una perspectiva distinta

'Éste es el tono de todo el libro primero del Novum Organum, dondo F. Bacon llega a afirmar: «lo vicjo, to aristotélico, sirve tan poco, que no puede mejorarse, sino que hay que sustituirlo por otras cosas».

2Así se expresa, por cjemplo, en su Digresión sobre los antiguos y los modernos: "Nos hemos beneficiado intelectualmente de los descubrimientos que vemos ante nuestros ojos, nos inspiramos también en to que han hecho los antiguos antes que nosotros, y aunque superemos al primer invertor, reconoccmos que él mismo nos ha ayudado a superarle.? 
sobre argumentaciones pasadas, aguijoneados por problemas de actualidad. Pues la relación que tenemos con nuestro presente se coimplica con la relación que tenemos con nuestra historia. Como escribía $C$. Thiebaut hace unos años: «Los clásicos son la otra cara del presente... Los clásicos no existen por sí mismos, o sólo existen en una inquietante neutralidad, como si no fueran tanto textos cuanto pretextuales, a la espera del acto lector interesado que les suministre actualidad, vigencia y sentido y deben su ser al afán de construcción del presente por medio de la construcción de un pasados ${ }^{3}$.

Si he escogido a Leibniz como pre-texto con el que dialogar en este trabajo, es porque su complejidad y riqueza argumentativas, su talante multidisciplinar, su curiosidad por todos los campos del saber y todas las culturas, permiten descubrir en su filosofía elementos esclarecedores para la reordenación de nuestra racionalidad práctica. El afán de Leibniz consistía en conectar las distintas ciencias para que cada una se complejizara y enriqueciera gracias a las demás, formando una especie de tejido o reticula en la que todo tenía que ver con todo, superando esa barrera especializadora que tanto lamentan actualmente filósofos de la ciencia e historiadores de las ideas ${ }^{4}$, pero sobre todo, haciendo de la actividad humana, de su transformación de la realidad y de las instituciones en aras de la consecución de una mayor felicidad, la meta de toda sabiduría, como muy bien refleja su lema «Theoria cum praxi». Pero lo que sin duda hace a Leibniz atractivo a la hora de encarar el problema de la racionalidad es que, en ese momento crucial de la «disputa entre antiguos y Modernos», él sigue dialogando de manera crítica con la filosofía antigua, fundamentalmente con Aristóteles, y con la cscolástica (lo que hace de él un «moderno antiguo», por jugar con la denominación actual de «moderno posmoderno» que aplicamos a los filósofos que no renuncian por entero a su tradición), pero además, mantiene correspondencia y/o critica las obras de todos los filósofos que gustamos de recordar como iniciadores de la Modernidad

"Cfr. Cabe Aristóteles, Visor, Madrid, 1988, p. 17. No muy alejado de esta perspectiva escribía Leibniz en Preceptes pour avancer les sciences: "En mis muchas investigaciones he encontrado a menudo que las opiniones de los más antiguos son las mejores, con tal de que se las interprete razonablemente», GP VII, 164. En adelente utilizare las siguientes abreviaturas para referirme a las obras de Leibniz: GP: C. I. Gerhardt, Die Philosophischen Schriften von $G$. W. Leibniz, Olms, Hildesheim, 1960. A: Sämtiche Schrifien und Briefe, hrsg, von der PreuBischen, bzw. der Deutschen Akademie der Wissenschaften zu Berlin, Darmstadt, 1923 ss; Leipzig, 1938; Berlin, 1950 ss. Opusc: Opuscules et fragments inédits de Leibniz, extraits des manuscrits de la Bibliothòque royale de Hanovre par Louis Couturat, Paris, 1903; reimpr. Hildesheim, 1966. Grua: Textes inédits, d'aprés les manuscrits de la Bibliothéque Provincial de Hanovre, publiés et anotés par G. Grua, 2 vols; Paris, 1948. VE: G. W. Leibniz, Vorausedition, zur Reihe VI in der Ausgabe der Akademie. Olaso: Escritos filosoficos, ed. de E. de Olaso, Buenos Aires, 1982. Echeverria: Nuevos ensays: sobre el entendimiento humano, ed. de J. de Echeverria, Alianza, Madrid, 1992.

* Cr. al respecto Creoffrey Lloyd: «La única manera que tenemos de empezar siquiera a poner a prueba la fuerza y la debilidad de cualquiera de estos u otros esquemas explicativos... consiste en mirar más allá del muro institucional que nuestras universidades han lexantado como barrera entre nuestras especializacionesw, citado por $\boldsymbol{F}$. Álvarez en kn una red de mundos plausibles. La urdimbre de la explicaciön», Isegoria, 11 (1995), p. 205. 
(Descartes, Spinoza, Malebranche, Hobbes, Locke, Thomasius, Wolff, Newton, etc.), comportándose como un auténtico hermeneuta, pues no se conforma con contraponer a sus adversarios lo que considera una teoría más potente, sino que también explica el atractivo que reviste el modelo que critica, desde un perspectivismo que en nuestros días le hace si cabe más encomiable, con la finalidad de iluminar y completar los saberes teóricos, orientando los prácticos.

Desde mi punto de vista, la actualidad de Leibniz (aparte de sus grandes intuiciones científicas que van reconociéndosele hoy día poco a poco) reside precisamente en esta «actitud racional», que me parcce digna de tener en cuenta en nuestros planteamientos éticos, en los que la fragmentación desemboca a veces en una excesiva simplicidad y la crítica de la arrogancia de la razón conduce a nuevos aislamientos, por emplear la terminología de M. Dascal ${ }^{5}$.

En mi ensayo sobre filosofía de la historia y en un par de artículos recientes ${ }^{6}$ me he ocupado de rastrear la «herencia negativa» de la filosofía leibniziana, cifrada en la adopción y universalización por parte de la filosofia de la historia de los principios de razón, perfección y continuidad. En el presente trabajo quisiera analizar la otra cara, lo que podría convertirse en la «herencia positiva» del pensamiento de Leibniz, más acorde con su talante ético. Para ello, pretendo rastrear en la filosofía práctica del pensador de Leipzig algunos elementos vertebradores de la racionalidad práctica de la Modernidad a los que, como se trasluce en nuestros actuales debates, no queremos ni debemos renunciar.

En un intento por equilibrar la balanza de la «herencia negativam, he decidido calificar de principios a estos elementos básicos que se coimplican y denominarlos: Principio de contingencia, Principio de autonomía y Principio de tolerancia. Todos ellos bajo el paraguas de un principio más amplio, el de pluralidad, que Leibniz enuncia como perspectivismo desde un punto de vista ontológico-gnoseológico en su Monadología: «Y como una misma ciudad contemplada desde diferentes lados parece enteramente otra y se halla como multiplicada en lo que respecta a su perspectiva, también ocurre que debido a la multitud infinita de las sustancias simples, hay como otros tantos universos diferentes que, sin embargo, no son más que las perspectivas de uno solo según los diferentes puntos de vista de cada mónada» ${ }^{7}$.

"Cfr. M. Dascal, «La arrogancia de la Razón», lsegoría, 2 (1990), p. 75.

- Crr. Entre Casandra y Cllo. Una historia de la filosofia de la Historia, Akal, Madrid, 1997. Cir. asimismo «Los "prolegómenos" del proyecto kantiano sobre la paz perpetua", en La paz y el ideal cosmopolita de la Ilustración. A propósito del bicentenario de Hacia la paz perpetua de Kant, ed. por. R. R. Aramayo, J. Muguerza y C. Roldán, Tecnos, Madrid, 1996, sobre todo pp. 150-154, y «Qué heredaron la Ética y la Filosofia de la Historia del laberinto leibniziano de la libertads, en Andilise, Lisboa (19) 1996, pp. $81-96$.

'Monadologia, \$57 (GP V1, 616; Olaso, 618). Cfr. al resprecto Nuevo Sistema, \$14 (GP IV, 484; Olaso, 468). Cfr. también Consecuencias metafisicas, Couturat, Opusc., 15 (Olaso, 509). 
La pluralidad de puntos de vista expresan metafóricamente la racionalidad «hermenéutica» de Leibniz a que antes he aludido y que se cifra en la captación de la pane de verdad presente en cada perspectiva de la realidad (la de los antiguos, la de los otros hombres doctos del momento, la de las otras variantes del cristianismo, la de las otras culturas). Se trata de un pluralismo que, sobre la base de su concepción de la contingencia y la individualidad, proporciona su fundamento a la idea de tolerancia, con tintes cosmopolitas e incluso multiculturales. La pluralidad de perspectivas será la mejor salvaguardia para aproximarse a la verdad libres de prejuicios y dogmatismos, no primando ninguna de ellas; sin embargo, en esta aproximación habrá que encontrar también un camino intermedio que no conduzca al relativismo, pues hay que conceder que no será lo mismo contemplar la ciudad desde el centro o desde los suburbios, desde su sistema de alcantarillado o desde un rascacielos, o, más aún, desde un helicóptero.

\section{NUDO}

\section{Principio de contingencia}

Hay que situar la defensa leibniziana de la contingencia en el momento en que las controversias teológicas en torno al libre albedrío y la predestinación están dejando paso a la polémica sobre la libertad y el determinismo natural. Los avances científicos mostraban un univcrso sujeto a leyes generales que permitían predecir los acontecimientos de la naturaleza, y si el ser humano formaba parte de ella, sus acciones debían estar sometidas al mismo determinismo causal. En la polémica entre la física y la matemática moderna, de un lado, y la metafísica, de otro, Leibniz adoptará hasta cierto punto el mecanicismo ${ }^{8}$, pero oponiéndose drásticamente al determinismo absoluto en todas

"Así afirma en Nuevo Sistema de la naturaleza y de la comunicación de las sustancias (publicado en el Joumal des Savants, 27 de junio de 1695), \$10, GP IV, 481: «Soy el hombre mejor dispuesto a hacer justicia a los modernos. Sin embargo me parece que han llevado la reforma demasiado Icjos, en parte por confundir las cosas naturales con las artificiales...» En los $\$ \$ 2$ y 3 acaba de reconocer su agradecimiento a la matemática y a los autores modernos por rescatarle del pais de la escolástica en que se habia internado demasiado, lo mismo que se habia liberado del yugo de Aristóteles; pero, ante la imposibilidad de explicarlo todo por el mecanicismo, decidió «convocar nuevamente o cómo rehabilitar las formas sustanciales, hoy tan desacreditadas, pero de un modo que las hiciera inteligibles y que diferenciara cl uso debido del abuso que se ha hecho de ellas" (GP IV, 461). Si hacemos caso de la referencias realizadas en Wilhelm Pacidits (esbozo de una autobiografía escrita en tomo a 1671-1672, en A VI, 2, 511) a los modernos que se está refiriendo aqui es a Bacon, Cardano, Campanella, Kepler, Galileo y Descartes. En el que Gerhardt considera último escrito filosofico de Leibniz, redactado poco antes de su muerte en 1716, expresa nuestro autor con contundencia: «... parece dificil descifrar completamente la opinión de los antiguos cuando no entran en el detalle de las cosas. Sin embargo, es bueno tenerks en cuenta y señalar las huellas de la verdad desde que ha comenzado a mostrarse a 
sus formas. Ahora bien, como Kant hará algunas décadas después, Leibniz critica severamente el estado de la filosofía, y particularmente de la metafísica, a la que considera «el lugar de todas las inconsecuencias y todas las ambigüedades" $"$, por lo que él decide convertirse en «reformador», emprendiendo la tarea analítica de precisar los términos, poniendo coto a las demostraciones incoherentes y aprovechando las intuiciones matemáticas para introducir rigor en las demostraciones.

Por otra parte, la clara oposición de Leibniz al determinismo tiene origen en su filosofía práctica de corte aristotélico, rotundamente expresada en su crítica de la Ética de Spinoza (quizá el único moderno que renuncia explicitamente a la libertad de las acciones): $« \mathrm{Si}$ todas las cosas existiesen necesariamente... se aniquilaría la filosofía moral ${ }^{10}$. Como Aristóteles, pondrá Leibniz el punto de partida de su argumentación en la distinción entre posibilidad y realidad; con otras palabras, la pluralidad de posibilidades de actuación será lo que constituya la condición sine qua non o la base de la libertad ". Por esta razón, cuando Leibniz polemiza con Hobbes y Spinoza ${ }^{12}$, como representantes más destacados del determinismo, su crítica se centra en la reducción que ambos hacen de la causalidad a la causalidad eficiente $y$, sobre todo, de la identificación que realizan entre posibilidad y necesidad, al afirmar Spinoza que todo posible existe necesariamente y Hobbes que lo que no llega a suceder nunca es imposible ${ }^{13}$. Leibniz sostendrá que la eliminación de las categorías modales de posibilidad y contingencia, así como la de finalidad, destruyen

los hombres" (GP VI, 624). Es de todos conocida la anécdota que el mismo Leibniz relata en una carta a Remond del 10 de enero de 1714: se paseaba por el bosque de Rosendal en Leipzig, a la edad de quince años, cuando descubrió que no podía encontrar las razones últimas del mecanicismo y de las leyes del movimiento en las matemáticas, y que habia que volver a la metafisica (GP III, 606); alude a ello también en cartas a Hartsoeker del 6 de febrero de 1711 (GP III, 519) y a Bourguet del 22 de marzo de 1714 (GP III, 568-569).

"Cfr. La reforma de la filosofia primera y la nocion de sustancia (1694), GP IV, 468 (Olaso, 455).

"Asi se expresa en su comentario de unas cartas de Spinoza ditigidas a Oldenburg: «Si omnia necessitate quadam ex divina natura emanant, omniaque possibilia etiam existunt, aeque facile male erit bonis ac malis. Tolletur ergo moralis philosophia» (A V1, 3, 365). Cfr. Teodicea, GP VI, 33. Cfr. Reflexions sur louvrage que M. Hobbes a publié en Anglois, de la liberté, de la necessite et du hazard, GP VI, 390.

"Por eso, partiendo del enunciado aristotélico: *Son contingentes las cosas que no son necesarias» (cfr. Confessio Philosophi, A VI, 3, p. 127; cfr. tambićn De necessitate et contingentia, VE 3, 455; cfr. asimismo Aristóteles, Primeros Analíticos, 1, 13-32 a 18-20), define lo necesario como aquello cuyo opuesto implica contradicción, esto $\mathrm{es}$, es imposible, mientras lo contingente será aquello cuyo opuesto es posible (cfr. Definición de libertad. GP VII, 108; Conversación con el obispo Stenon acerca de la libertad, VE, 302, y Conversación sabre la libertad y el destino, Grua, 478, todos traducidos en mi edición Escritos en tomo a la libertad, el azar y el destino, Tecnos, 1991. Cfr. asimismo Couturat, Opusc, 17).

1" Muchos interpretes han pretendido aproximar las teorias de Spinoza y Leibniz, y, sin duda, encontramos algunos puntos en los que Leibniz está en deuda con Hobbes. Pero por lo que respecta a la teoria de la contingencia, Leibniz es crítico con ambos.

"Cfr. Teodicea. $\$ 172$, GP V1, 216-217. Cfr. también carta a Nicaise, 15 de febrero de 1697 (GP 11, 563) y carta a Philippi, enero 1680 (GP IV, 283). 
la condición básica de la libertad, reduciendo ésta a la mera ausencia de coacción externa, es decir, a la realización necesaria de un acontecimiento si nada cxterno al sujeto se lo impide. En su recensión del libro de Hobbes sobre la libertad y la nccesidad, comenta Leibniz que es una concepción bastante aceptable considerar libre una cosa cuando su poder no se ve limitado por una instancia cxterna, pero no le parece suficiente, pues esto concerniría tanto a sustancias inteligentes como no inteligentes ${ }^{14}$, es decir, se estaría confundiendo espontaneidad con libertad. Para Leibniz, la libertad de coacción, ya sea externa (por ejemplo, estar enfermo o en prisión) o interna (por ejemplo, dominado por las pasiones) ${ }^{15}$, constituye un elemento primordial, pero no basta para la construcción de una teoria de la libertad.

La contingencia no es, pues, sólo un principio metafísico, sino ante todo un principio moral, que posibilita la libertad de los sujetos y, como consecuencia, la imposibilidad de predicción de sus acciones. En este sentido, a lo largo de sus escritos se opondrá Leibniz a la idea de que toda actividad del hombre sca inútil porque todo ocurra inevitablemente, esto $\mathrm{es}$, la concepción clásica del destino que Crisipo había caracterizado como «argós logós», es dccir, la «razón perezosa» recogida en el mundo mahometano, por la que «todo lo que ha de ocurrir, ocurrirá necesariamente obres o no obres» ${ }^{16}$, hagas esto o aquello. Para el pensador de Leipzig, por el contrario, la acción humana no sólo es libre, sino que se dice de muchas maneras y de ella depende la historia humana, individual y social.

Sin embargo, los problemas se le multiplican a Leibniz cuando emprende la justificación de Dios en su Teodicea, tomando la perspectiva del absoluto en su defensa del «mejor de los mundos posibles» o de la «armonía preestablecida" " . En efecto, la afirmación realizada en la Teodicea de que "todo es cicrto y se encuentra determinado con anterioridad tanto en el hombre como en el resto de las cosas, de manera que aquello que va a sucedernos en cl futuro es verdadero desde toda la eternidad y puede ser previsto por

" En sus Réflexions sur louvrage que $M$. Hobbes a publié en Anglois, de la liberté, de la necessité at du hazard, comenta Leibniz el libro de Hobbes Questions conceming liberty, necessity and chance (1656), que era el resultado de su polémica con el obispo irlandés de Derry, John Bramball, un defensor bastante moderado del libre albedrío que había escrito un ensayo titulado $A$ defense of the Thrue Liberty of Human Actions (1655), para oponerse al anterior libro de Hobbes of liberty and necessity (1654). En este punto, cfr. Réflexions, GP VI, 391.

is Cfr. carta a Coste, 19 de diciembre de 1707 (GP III, 401), y Nuevos Ensayox, II, 21, \& 8 (A VI, 6, 167; Echeverria, 199).

15 Cfr. Confessio philosophi, A VI, 3, 129; cfr. también Discurwo de Metafísica, \& 4, GP IV, 429-430, y Vindicatio Causa Dei, \& 106, GP VI, 454.

"A lo largo de su obra, Lcibniz sc queja a menudo de haber sido malinterpretado, imputándosele que defiende la necesidad absoluta y el fatalismo, cuando todos sus esfuerzos ban ido a clarificar los términos y a mostrar la verdadera diferencia entre libertad, contingencia y espontaneidad de un lado, y necesidad absoluta, azar y coacción por otro; cfr. Quinto Escrito a Clarke, $\S 2$, GP VII, 389. 
Dios con infalibilidads ${ }^{18}$, no parece dejar mucho campo para la contingencia de las acciones humanas.

En mi opinión, sólo hay una manera de salvar la contingencia en Leibniz y es acudiendo a la noción de «hipótesis metafísica». Cuando nuestro autor se refiere a su teoría de la «armonía preestablecida» lo hace en ocasiones con el calificativo de «hipótesis» o «supuesto» ${ }^{19}$. Y, como él mismo afirma, «establecer una hipótesis o explicar el modo de generación de algo no es más que demostrar la posibilidad de ese algo» ${ }^{20}$. Y en las demostraciones que proceden de proposiciones concedidas o de hipótesis, lo único que hay que hacer es mostrar qué hipótesis se contradicen entre $s^{21}$. Ahora bien, una vez demostrada la coherencia, esto es, que la argumentación se desarrolla en una debida forma lógica, no puede olvidarse que las conclusiones obtenidas son hipotéticas ${ }^{22}$, lo que en lenguaje popperiano equivaldría a afirmar que «están sujetas a la falsación».

Siendo coherente, Leibniz ha de considerar sus «hipótesis metafísicas» como una hipótesis más que concursa con el resto (por ejemplo, la «hipótesis de las causas ocasionales») en la explicación de la posibilidad de las cosas. En anteriores trabajos me he ocupado de un pormenorizado análisis intratextual de cstas complejas tesis leibnizianas, que no incurren en incoherencia, y que surgen de poner en conexión la polémica del libre albedrio humano y de la presciencia o providencia divinas con su teoria de la verdad y con el cálculo infinitesimal ${ }^{23}$. Ahora sólo quisicra subrayar el carácter contingente mismo de este discurso leibniziano, que él mismo no dudaría en calificar de «explicaciones plausibles» que, además, sólo han lugar en el supuesto de que Dios cxista y haya creado el mundo, pues entonces y sólo entonces - no olvidemos el subtítulo de la Teodicea - habría que justificar la bondad de Dios y la existencia del mal en el mundo.

Haciendo el esfuerzo hermenéutico de poner esa perspectiva trascendente entre paréntesis, adoptando la pluralidad de perspectivas del mundo sublunar, comprenderemos que lo mismo sea considerado por Leibniz como «hipotéticamente necesario» desde el punto de vista de lo absoluto y como «absolutamente contingente» desde la perspectiva humana. Su talante racionalista

18 $\$ 52$, GP VI, 131.

${ }^{19}$ Cfr. Nuevo Sistema, $\$ 15$, GP IV, 485, o Monadologia, $\$ 59$, GP VI, 616. Cfr. tambièn GP I, 149: «... per suppositionem sive hypothesin...»,

Sobre la sintesis y el analisis universal, GP VII, 295.

"Cfr. Sobre los principios (post. a 1683), en Couturat, Opusc, 184.

" Meditaciones sobre el conocimiento, la verdady las ideus, GP IV, 426.

${ }^{27}$ Cfr. mi intraducción a la edición de textos de Leibniz, Escritos en torno a la hibertad, el arar y el destino, Tecnos, Madrid, 1991, pp. IX-LXXVII. En su teoría de la verdad, que consiste en la inclusión del Predicado en el Sujeto, es Leibniz también deudor de Aristóteles: Analíticos posteriores, A IV, De interpretatione, 17a, y Categorias, 1a. Cfr. Couturat, Opusc, 519. Sin embargo, la afirmación de que tambiẻn en las verdades contingentes el Predicado está incluido en el sujeto, se la debe Leibniz al conocimiento que le proporciona la geometría y el cálculo infinitesimal. 
no le impide a Leibniz resaltar la importancia de la experiencia a posteriori ${ }^{24}$, que en los seres humanos debe suplir en la mayoría de los casos a las razones a priori, y siguiendo este modelo científico, afirmará que hay que aceptar que la libertad es un factum, que no está sujeta a ningún determinismo y que cabe elegir el mal, por lo que «la hipótesis que hay que demostrar es la de la necesidad y no la de la libertad, ${ }^{25}$.

Todo en el universo es contingente, pero lo que es contingente por antonomasia es la historia, es decir, aquello que depende inmediatamente de la acción humana, que consigue en gran medida zafarse del determinismo natu$\mathrm{ral}^{36}$ : «Porque los seres libres o inteligentes no están atados a leyes subaltcrnas determinadas del universo, sino que actúan por la sola espontaneidad de su propia potencia y, a raíz de la intuición de alguna causa final, interrumpen la conexión y el curso de las causas eficientes sobre la voluntad. Y esto es tan cierto que ninguna criatura es "kardiognostés" (el que conoce los corazones), capaz de predecir con certeza qué ha de elegir alguna mente conforme a las leyes de la naturaleza, al modo como en otros casos puede ser predicho qué ha de efectuar un cuerpo dado si el curso de la naturaleza no se interrumpe $\gg$ " $\mathrm{Y}$, desde luego, Leibniz está convencido de poder intervenir en la realidad histórica: de ahí sus actividades políticas para contribuir a la reunión de las iglesias, o sus empresas de fundación de Academias científicas. La teoría de la libertad leibniziana será, pues, una teoría de la acción que no puede conformarse con ganar espacio al determinismo natural, sino que apunta a lo que realmente puede hacer el ser humano, a esa creatividad radical que sale de su propio fondo plasmándose en controversias teóricas que adquieren su validez de su capacidad para influir en la práctica. Algo que quedará más claro analizando el segundo principio.

\section{Principio de autonomía}

Antes de seguir adelante, quisiera decir que Leibniz no utiliza el concepto de autonomía en ninguno de los sentidos polisémicos a que estamos acostumbrados $-\mathrm{y}$ que tan bien ha analizado recientemente A. Valdecantos- ${ }^{28}$. Sin cmbargo, en la rotundidad de su idea de individuo están apuntados algunos de estos aspectos fundamentales, si cabe con un atisbo de realidad que

\footnotetext{
${ }^{24}$ Cr. De necessitate et contingentia, VE $3,456$.

${ }^{25}$ Quintín Racionero, "La racionalización de la política», Revista Latinoamericana de Filosofia, XVIII, núm. 1, otoño 1992 , p. 96.

36 Leibniz afirma, criticando el artículo 6 de los Principia de Descartes: «No tenemos libre arbitrio al percibir, sino al actuar» (GP IV, 357).

${ }^{27}$ Verdades necesarias y contingentes, VE 3,459 (Olaso, 333). A esto denominará Kant «causalidad por libertad».

${ }^{23}$ Cfr. «Equilibrio reflexivo en tomo a la autonomía», El individuo y la historia, Paidós, Barcclona, 1995, pp. 99-131.
} 
perderá el enfoque «trascendental» kantiano. La individualidad de los seres humanos significará para Leibniz la autonomía de los mismos frente a la naturaleza, y respecto al resto de sus congéneres en la toma de decisiones morales.

Singularidad y autarquía serán los rasgos que caracterizarán a los seres individuales. Ahora bien, este fenómeno que impide que haya dos individuos absolutamente iguales ${ }^{29}$ en la naturaleza y que consiste en que «las acciones nazcan de su propio fondos ${ }^{30}$ no es para Leibniz en sentido estricto algo privativo del ser humano, sino que corresponde a todos los seres vivos ${ }^{31} \mathrm{y}$ puede explicarse como un mero despliegue de virtualidades que se hallan de alguna manera preformadas en su semilla originaria, tal y como había sido demostrado en las investigaciones realizadas en biología ${ }^{32}$. Esta idea, que en su más drástica formulación metafísica -- «las mónadas no tienen ventanas»_ ${ }^{33}$ condujo a todo tipo de críticas y ridiculizaciones, albergaba la intención de mostrar la autosuficiencia de los seres vivos, que se identificará con la espontaneidad de sus acciones en animales y plantas, y con libertad o autodeterminación de las mismas en los seres humanos. La gradación que se observa en la jerarquía de los seres vivos depende de la complejización creciente de sus respectivas facultades perccptivas, expresándose en sus distintas acciones, que van del mero despliegue genético a las conductas instintivas más elaboradas.

${ }^{29}$ Fenómeno que tiene su más clara expresión metafísica en el «principio de los indiscernibles» (no puede haber en la naturaleza dos cosas singulares diferentes sólo en número) con cl que Leibniz pretende renovar el principio escolástico de individuaciôn. Cfr. Verdades primèras, Couturat, Opusc., 519 (Olaso, 341). En Sobre la naturaleza misma..., publicado en Acta Eruditorum en septiembre de 1698, escribe Leibniz; «... jamás en parte alguna se da una semejanza perfecta (lo que debe ser considerado como uno de mis axiomas nuevos y más importantes)». Respecto al principio escolástico, v. referencias que hace Olaso en notas 98 y 99 de p. 141. Cfr. también el $\$ 9$ del Discurso de Metafisica: "Cada sustancia singular expresa el universo entero a su manera y en su noción cstán comprendidos todos sus acontecimícntos, todas las circunstancias y todo el curso de las cosas exteriores» (GP IV, 433).

* Cr. Carta a Arnauld, GP II, 136.

"Cfr. Teodicea, \$ 291, GP VI, 289. Cfr, asimismo Discurso de Metafisica, § 32, GP IV, 458; Monadologie, \$ 18, GP VI, 609-610. Cfr. también Couturat, Opusc., 14.

${ }^{32}$ eL $\mathrm{x}$ n filossofos han estado muy perplejos respecto del origen de las formas, entelequias o almas: pero hoy, cuando se ha advertido merced a investigaciones exactas, realizadas en plantas, insectos y animales, que los cuerpos orgánicos de la naturaleza jamás han sido producto de un caos o de una putrefacción, sino siempre de semillas en las que sin duda hay alguna prefomación, se ha juzgado que antes de la concepción no sólo existía ya el cucrpo orgánico sino incluso un alma en ese cuerpo y, en una palabra, el animal mismo», Monadologia, \& 74, GP VI, 622. Leibniz está siguiendo muy de cerca las investigaciones llevadas a cabo en biologra a finales del siglo xvil y que suponen una reacción contra la concepción mecanicista de la vida, en particular de la biologia cartesiana: teoria del animal máquina y formación mecánica del ser viviente. Cabe mencionar a Ch. Perrault (De la méchanique des animaux, 1680), Swammerdam y Leeuwenhoeck, todos coincidiendo en afirmar que el animal es una máquina, pero que posee un principio de vida - alma- y una estructura tan compleja que no es admisible que se haya formado sólo por el juego de las leyes del movimiento. Cfr. también Causa Dei, \& 83, GP VI, 549.

3 Cfr. Monadologia, \$7, GP VI, 608. 
Pero sólo los seres humanos «se elevan al grado de la razón» ${ }^{34}$, en tanto que la percepción se convicrte en apercepción, es decir, «conciencia o conocimiento reflexivo del estado interior» ${ }^{35}$. Para no topar con la Iglesia, Leibniz no se atreve a ser demasiado explícito en su afirmación de la preexistencia de la capacidad racional ${ }^{36}$, pero en cualquier caso, lo que aparece claro es que el desarrollo de esta capacidad nos proporciona un ser cualitativamente distinto del resto de los animales: "Los que llamamos animales razonables y que... son capaces de realizar actos reflexivos y de considerar Io que llamamos yo, sustancia, alma, espíritu, en una palabra, las cosas y las verdades inmateriales; y por eso podemos poseer ciencias o conocimientos demostrativos» ${ }^{37}$. Según esto, aunque los seres humanos continúan siendo en sus tres cuartas partes animales, su razón les abre la puerta de la libertad, de manera que su autoconciencia o apercepción les hace capaces de romper el automatismo de la serie de sus percepciones convirtiendo la mera autarquía en autorrealización al dotar a su pensamiento y a su acción de fines reflexivos propios, y pudiendo enfrentarse a la naturaleza con creatividad (trasunto de la creación divina).

Dejando ahora a un lado sus agudas connotaciones lógicas, y que hacen referencia a la tcoría de la verdad leibniziana, la famosa tesis que escandalizó a Arnauld, a saber, «que la noción individual de cada persona encierra de una vez para siempre lo que ha de ocurrirle» ${ }^{38}$, lejos de abocar al determinismo, viene a subrayar - desde esta perspectiva - la libertad de los seres racionales, su capacidad para inclinarse por una determinada acción, lo que más tarde será calificado por Kant como «causalidad por libertad». Pero además constituye la fundamentación de la identidad individual, al mostrar la continuidad de percepciones y acciones del yo a lo largo de su existencia, como afirma en los Nuevos ensayos: «En cada sustancia, el futuro tiene una ligazón perfecta con el pasado, y en esto consiste la identidad del individuo ${ }^{39}$. Así, la inquietante expresión leibniziana «el presente está preñado de futuro», lo que significa es que «todas las sustancias simples contienen... una suficiencia (autárqueia) que las convierte en fuentes de sus acciones» ${ }^{40}, 0$, con otras palabras, «actúan

${ }^{*}$ Cfr. Monadología, $\$ 83$, GP VI, 621 (Olaso, 624). Cfr. también Principios de la Naturaleza y de la Gracia, \&4, GP VI, 599-600 (Olaso, 599).

3s Principias de la naluraleza y de la Gracia, $\$ 4$, GP VI, 600. Descartes y Spinoza no distinguian lo suficientemente entre conciencia y autoconciencia. Leibniz fue el primero en hacerlo, acuñando para el nuevo concepto el término «apercepción», que opone al de «percepción».

${ }^{3}$ *... no se afirma cierta preexistencia de la racionalidad; pero puede considerarse que en los gérmencs preexistentes ya habian sido preestablecidos alguna vez y preparados por Díos no sólo el organismo humano sino ta racionalidad misma mediante el ejercicio de un acto, por así llamarlo selladow, Causa Dei, \$82, GP VI, 451.

${ }^{37}$ Principios de la Naturaleza y de la Gracia, $\$ 5$, GP VI, 601; los subrayados son míos. Cfr. Monadologia, $\$ 30$, GP VI, 612 .

${ }^{39}$ Discurso de Metafísica, $\$ 13$, GP IV, 436. Cfr. Verdades primeras, Couturat, Opusc, 520.

${ }^{19}$ Nuevos Ensayos, II, 1, \$ 12 (GP V, 104; Echeverría, 118-119).

Monadologia, \$18, GP VI, 610 . 
siguiendo sus propias leyes internas» ${ }^{41}$, lo que en la más compleja constitución humana vendrá a significar que nuestra «libertad de acción tiene estructura arborescente, y que... al decidirnos en el presente entre varias líneas de conducta rivales, estamos determinando las opciones que quedarán disponibles en el futuro», o, dicho de otra manera, que el yo se autoproduce o se autodestruye a través de la secuencia de sus elecciones ${ }^{42}$.

Al afirmar que «la razón es la raíz misma de la libertad», caracterizada como «espontaneidad inteligente» ${ }^{43}$, lo que pretende Leibniz es perfilar los márgenes de esa autarquía racional humana que se expresa en la autodeteminación, esto es, en la «determinación a actuar por motivos racionales orientados por la representación del bien» ${ }^{44}$. Con otras palabras, la libertad consistirá en la "determinación racional» de la voluntad encaminada a la autorrealización del individuo, que viene a sustituir al mero despliegue instintivo del resto de los seres vivos. Como he escrito en otros trabajos, la salida leibniziana del laberinto de la libertad consiste en combatir el determinismo natural con la instauración de un determinismo racional que el ser humano se autoimpone, algo que nos hace evocar prospectivamente aquel «círculo vicioso» mencionado por Kant en la Fundamentación de la metafisica de las costumbres: «Nos consideramos libres en el orden de las causas, para pensarnos sometidos a las leyes morales en el orden de los fines» ${ }^{45}$. Sin embargo, este determinismo, consistente en la autoimposición de leyes racionales de actuación, que en sí mismo constituye una limitación de las acciones, es la única manera en que el individuo puede liberarse de la incertidumbre que le acosa por doquier; la autodeterminación será la forma en que los seres humanos intenten buscarse un campo más res-

${ }^{4}$ «EI alma sigue sus propias lcyes, y los cuerpos también las suyas... Las almas actúan según las leyes de las causas finales mediante apeticiones, fines y medios. Los cuerpos actúan según las leyes de las causas eficientes o de los movimientos", Monadologiu, $\$ 878$ y 79, GP VI, 620 . Cfr. Principios de lo Naturaleza y de la Gracia, \&3, GP VI, 599.

"2 J. A. Rivera, «Paradojas de la abyección», Individuo e historia, pp. 63 y 76.

47. Cr. Definición de libertad, GP VII, 108. En este sentido, me parece un grave error de Gabaude afirmar que todas las mónadas poseen libertad: «En attribuant les facteurs de la liberté à toute monade, Leibniz adopte une position naturaliste et anticartésienne», en Liberté et raison, vol. III, Philosophie justificatrice de la liberte, Toulouse, 1970-74, p. 288. Su aserto contradice la tesis leibniziana - -que vamos examinando- de que la libertad implica elección y deliberación, cosa que no todas las mónadas poseen. En el \$288 de la Teodicea proporciona Leibniz lo que podemos considerar como su definición definitiva de libertad: «... consiste en la inteligencia, que envuelve un conocimiento distinto del objeto de la deliberación, en la espontaneidad, con la que nos determinamos, y en la contingencia, es decir, en la cxclusión de la necesidad lógica o metafísica. La inteligencia es como el alma de la libertad, y el resto es con respecto a ella como el cuerpo o la basc», GP VI, 288.

4 La razón muestra al hombre la manera de zafarse del determinismo impuesto por las fuerzas de la naturaleza (p. ej., un terremoto) o por nuestra propia constitución (desde las constricciones impuestas por nuestra cadena genética hasta las más elaboradas pasiones), mediante la aplicación de sus conocimientos al dominio y control de la naturaleza, o mediante la aplicación de su capacidad reflexiva al conocimicnto y dominio de si mismo, para mejor seguir sus fines racionales orientados a la consecución del bien. Y en eso consiste la libertad.

Ak. IV, 450 . 
tringido de seguridad operativa, una acotación frente a la plural y a veces dolorosa contingencia que nos rodea; así entiendo la afirmación realizada recientemente por Axel Honneth, quien considera el principio de autodeterminación como una forma de organización de las fuerzas contingentes sobre las cuales el individuo no tiene completo control, pero que no son inmunes a la intervención de la acción racional ${ }^{46}$.

Con su teoría de la libertad como determinación racional combate Leibniz el sensualismo de Locke ${ }^{47}$, para quien el único móvil de la acción será la satisfacción del yo, pero se encuentra también bastante alejado del rigorismo de Kant, para quien el único móvil de la buena voluntad es el deber. Sin duda, la ética de Leibniz carece de la elaboración de la kantiana, pero a cambio nos permite permanecer inmersos en el mundo real, todo lo teñido que lo queramos de metafísica, pero sin sujetos trascendentales. El Reino de la Gracia «es un mundo moral en el mundo natural» ${ }^{48}$, lo que quiere decir que la moral no es independiente de lo que sucede en el mundo y que el concepto de bien y de justicia que se baraja incluye lo sensible y la felicidad. Leibniz aún no ha introducido la asepsia kantiana, que tan buenos resultados proporciona a la ética en el laboratorio de su formalismo, de manera que los seres humanos continúan sumidos en la conciencia de su «racionalidad imperfecta», aproximándose a su autorrealización en un proceso «mixto», en un progreso continuo e ininterrumpido hacia un ideal de perfección que dura toda su vida.

Pues los seres humanos, aun rigiéndose en sus actuaciones por el principio de perfección, no siempre eligen lo que es lo mejor -como haría una razón que estuviera situada en el punto de vista del absoluto--, sino que se decantan en cada situación por «lo que mcjor les parece». Es el precio que los seres humanos deben pagar por no ser «yoes desencarnados», ya que en la concepción leibniziana el individuo constituye una unidad en la que existe continuidad entre sensibilidad y razón. Precisamente esta coexistencia de preferencias sensibles y racionales es lo que complejiza las acciones humanas y, por otra parte, lo que libera a los individuos de convertirse en "autómatas previsibles».

La importancia del principio de autonomía tal y como la hemos analizado radicaría, pues, en el protagonismo del individuo en la vida práctíca: sólo el individuo es responsable de sus decisiones y acciones, que conducen a su autorrealización. Con otras palabras, los sujetos de la ćtica son los individuos. Ahora bien, esos mismos individuos sólo desarrollan su historia propiamente humana en su proyección social. El principio de tolerancia (a que me referiré

"Gr. "Decentered Autonomy, the Subject after the Fall", comunicacion presentada en el Coloquio ala modernité en question chez Habermas et Rortys, Cérisy-La-Salle, Francia, julio 1993.

47 Mme. de Staēl resalta el genio de Leibniz, subrayando que su valor consiste en wabet mantenido la filosofía de la libertad moral contra la de la fatalidad sensual», De l'Allemagne, II, 125.

18 Monadologia, \$ 86, GP VI, 622 . 
a continuación) constituiría, en este sentido, la otra cara del principio de autonomía.

\section{Principio de tolerancia}

Con palabras de Leibniz: «Aunque cada uno de nosotros es diferente de los demás en virtud de su individualidad, debemos recordar, sin embargo, que ningún ser humano podría subsistir solo por sí mismo, y no le estamos considerando únicamente como una parte de la creación, sino desde ese aspecto particular de la superficie terrestre que es la Politie, sociedad y género, a los que estamos ligados por domicilio, familia u otras comunidades» ${ }^{49}$. El instinto egoísta primario, el propio interés se encontratía, pues, a la base de la relación social, pero un posterior análisis racional nos muestra las excelencias, también individuales, que obtenemos de la cooperación con nuestros congéneres en la consecución del bien común ${ }^{50}$. Lo que, desde la esfera de la ética (el Reino de la Gracia), que se fundamenta en el principio de la justicia, se traduce en «procurar al mundo el mayor bien que podamos» ${ }^{51}$. Victoria Camps se expresó no hace mucho en términos similares, al afirmar: «la ética no es otra cosa que el deseo de producir el bien y reducir la cantidad o la calidad de mal en el mundos ${ }^{52}$.

Por consiguiente, dirá Leibniz, «la place d'autruy constituye el verdadero punto de perspectiva tanto en política como en moral» ${ }^{53}$, al ser el único principio capaz de dar concreción a la idea de justicia. Adelantándose a las reticencias kantianas ${ }^{54}$ contra este principio, que no es otro que la clásica «Regla de oro» de origen cristiano, emprende Lcibniz la demostración de verdad del mismo. Hasta Locke se había aceptado esta regla como un principio evidente y el inglés se atreve a insinuar tímidamente en forma de cuestión que no es absurdo exigir una fundamentacion de la misma ${ }^{55}$, pero Leibniz da un paso más adelante en la intención crítica al afirmar que no sólo precisa de prueba, sino también de explicación ${ }^{56}$. Por utilizar la terminología de Hans Reiner, tanto Leibniz como Kant criticarían esta regla moral en su aspecto de "proyección afectiva» (como una especie de mecanismo instintivo que funciona

49 De vita beata, GP VII, 93.

${ }^{5}$ En Nuevos Ensayos, III, 1, 1, al hilo de su crítica Hobbes, por no aceptar la idea aristotélica de sociabilidad del hombre, insiste en el sentido cooperativo de las comunidades humanas (GP V, 253; Echeverría, 317). En cl Discurso sobre la generosidad afirmará: «No estamos hechos para nosotros mismos, sino para la sociedad * (GP VII, 107).

si Ibid., GP VII, 107.

sz Cfr. "Por la solidaridad hacia la justicia», en La herencia ética de la Ilustración, Carlos Thiebaut (ed.), Crítica, Barcelona, 1991, p. 137.

${ }^{53}$ A IV, 3, 903.

s4 Cfr. Fundamentación de la Metafisica de las costumbres, Ak. V, 430.

ss Cfr. Essay concerning human understanding, I, 2,4 .

* Nuevas Ensayos, I, 2, 4; Echeverria, 91. 
sintiendo compasión por el malhechor que ha sido condenado a una pena), ya que la verdadera reciprocidad tiene un fundamento reflexivo, y ambos reconocerían la incapacidad de esta regla para convertirse en una ley necesaria. Ahora bien, mientras que Kant pondrá en su lugar el imperativo categórico (que gana en abstracción y universalidad alejândose de la realidad), Leibniz subrayará que, a pesar de sus limitaciones teóricas (que nos reducen a la probabilidad de los casos concretos), la importancia del principio de sla place d'autruy» reside, por una parte, en su utilidad práctica y, por otra, en que nos permite inferir la idea general de justicia. Es decir, a falta de poder obtener el «punto de vista objetivo o imparcial» -que recientemente han perseguido autores como Thomas Nagel - Leibniz afirmará que debemos conformarnos con este principio que nos enseña que «el lugar del otro es el punto de vista verdadero para juzgar equitativamente cuando se pone uno en él» ${ }^{57}$, al mostrarnos como «sospechoso de injusticia todo to que encontraríamos injusto si estuviéramos en el lugar del otro, a la vez que nos hace examinar con detenimiento aquello que desearíamos si estuviésemos en ese lugars ${ }^{58}$.

La obvia vinculación de esta regla con el principio de justicia es lo que hizo que se le concediera más importancia entre los seguidores de la doctrina filosófica del derecho natural en el siglo xvIr y la Ilustración, como Hobbes, Locke y, especialmente, Thomasius ${ }^{59}$, aunque también Voltaire, Rousseau e incluso Herder ${ }^{60}$ la mencionaran. Sin embargo, la crítica kantiana consiguió erradicarla del panorama alemán, salvo la alusión realizada por Schopenhauer, precisamente para caracterizar al imperativo categórico como «expresión figurada de esta misma regla» ${ }^{61}$.

Lo que yo quiero mostrar a continuación es que esta máxima, en su formulación leibniziana, además de la idea de justicia, subraya el concepto de tolerancia. Pues «ponerse reflexivamente en el lugar del otro» constituye la piedra de toque de nuestro reconocimiento de los demás como semejantes, haciendo que cada individuo se entienda a sí mismo como uno más entre otros, advirtiendo una pluralidad de visiones del mundo y sin privilegiar ningún punto de vista; es el reconocimiento de que todo individuo esconde algo valioso en sí y que se expresa en sus puntos de vista -idea que se encuentra, por ejemplo, a la base de la concepción del respeto de Tugenhadt ${ }^{62}$. Este aspecto

${ }^{57}$ Nuevos Ensayos, 1, 2, 4; Echeverría, 92. En La place d'autruy había concluido: «El scntido del principio seria: no hagas o no rechaces lo que no quieras que se te haga o se te rechace» (A IV, 3, 904).

5* A IV, 3,904.

${ }^{9}$ Cfr. Hobbes, Elements of Law and politic, I, 17, 9, y De cive, cap. III, \$\$ 14 y 26 . Locke, Essay conceming human understanding, $\mathrm{I}, 3, \S 4$ y 7 . Thomasius, Fundamenta juris naturae et gentium, I, II, $\$ \$ 40-42$.

* Cfr. Voltaire, Essai sur les moeurs, Oeures completes, 12, Paris, 1878, p. 370; Rousseau, Discours sur l'origine de l'inégalite, $1{ }^{a}$ parte; Herder, Ideen zur Philosophie der Geschichte der Menschheit, IV, 6, 3 .

(4) CFr. El fundamento de la mord, \$7.

- Tal y como aparece en su obra traducida al castellano bajo el título Problemas de la ética. 
de la teoría leibniziana se nos presenta como una anticipación del pensamiento de Stuart Mill, al considerar el pluralismo como algo deseable por sí mismo, como un interés por lo diferente que no sólo se refiere a otros individuos, sino también a otras culturas, en una incansable búsqueda del perfeccionamiento y el progreso que podrían proporcionar al género humano no sólo el complemento, sino también el contraste. $\mathrm{Y}$ aquí aparece a su vez subrayado el principio de autonomía o individualidad a que nos refcríamos.

El interés de Leibniz por entrar en contacto con el mayor número de concepciones del mundo posibles, intentando comprenderlas, queda reflejado en su correspondencia, dirigida no sólo a las personas doctas del mundo occidental - hecho del que no quedan excluidas las mujeres-, sino que se hace extensiva a otras culturas. Así, tanto en su correspondencia con los jesuitas en China como en sus Novissima Sinica (1697) muestra Leibniz su interés por obtener un intercambio cultural con esta civilización que guardaba tesoros inigualables y en la que descubría tantas concomitancias con el pensamiento occidental: por ejemplo el $L i$ de la teología china que interpreta (lo mismo que Malebranche) como la razón universal sobre la que están fundamentados el orden natural y las reglas del derecho ${ }^{63}$, o el $I$ Ching que guardaba profundísimas relaciones con el sistema binario o el cálculo diádico, que Leibniz inventó y que hoy día constituye el lenguaje básico de la informática ${ }^{\text {ít. }}$. Para favorecer el intercambio de saberes llega a proponer en una carta a Bourguet de 1710 que se creen escuelas en Europa donde los chinos enseñen a los europeos, pues éstos -convencidos de su superioridad - no se preocuparían de otra manera por informarse sobre los progresos chinos ${ }^{65}$. Por una parte, Leibniz quiere completar la perspectiva occidental para elaborar una Enciclopedia Universal lo más exhaustiva posible, proyecto que vendría a completar la tarea acometida por las Sociedades científicas. Pero, en definitiva, lo que lc interesa es descubrir los aspectos positivos y enriquecedores que subyacen a toda elaboración racional.

La propuesta leibniziana consiste - como he escrito recientemente en mi artículo «Las raíces del multiculturalismo en Leibniz»- en un diálogo de credos y culturas para construir un saber enciclopédico (teoría) y con ello contribuir a mejorar las condiciones de vida de la humanidad (práctica), tanto en su vertiente material como espiritual. Cada cultura representa una concepción del mundo, una perspectiva de la misma realidad y la cooperación es el único camino para lograr una visión unitaria del conjunto, una comprensión de los elementos básicos y fundamentales del universo y su sentido, sin suprimir la

*3. A. Robinet, G. W. Leibniz. Le meilleur des mondes par la balance de l'Europe, PUF, Paris, 1994, p. 291.

* Cfr. J. Echeverría, Leibniz, Barcanova, Barcelona, 1981, p. 112.

${ }^{\text {is }}$ Cfr. GP III, 550. 
diversidad, pues armonizar no significa uniformar, sino comprender la diversidad, como indica su lema «multiplicidad en la unidad» ${ }^{66}$.

Ahora bien, para Leibniz la tolerancia tiene sus límites, pues no pueden alentarse el mal y el dolor en el mundo. La mayor responsabilidad humana, dirá, es «procurar, en cuanto de nosotros dependa, que lo que aún no ha ocurrido se disponga lo mejor posible ${ }^{67}$. De la libertad humana depende la ordenación del porvenir, lo que supone meditar acerca de las creencias que uno va a seguir ${ }^{6 *}$. Por eso, la adopción del punto de vista del otro no puede consistir en el abandono de nuestras creencias ni de nuestra capacidad crítica para juzgar las ajenas ${ }^{69}$. Con otras palabras, hay que respetar la libertad de pensamiento, pero no abandonarla a sí misma, sino criticar, incluso con dureza, las ideas perniciosas y su propagación. En esto se cifra la crítica de Lcibniz a Locke, cuya Carta sobre la tolerancia había sido un documento importante para Leibniz salvo en un punto: la inhibición de combatir hasta las ideas peores y más extravagantes; ahora bien, añade Leibniz en los Nuevos Ensayos, no ha de confundirse la lucha contra las ideas con la agresión hacia los individuos que las defienden ${ }^{70}$. Leibniz tiene en mente cuando escribe estas líneas tanto el influjo malévolo de algunas sectas religiosas como las reacciones dogmáticas y sangrientas de las ortodoxias imperantes (recordemos la Inquisición o la quema de brujas llevada a cabo también entre los protestantes).

Desde el punto de vista leibniziano, nadie puede arrogarse la certeza absoluta de todas sus creencias, e incluso entre las religiosas habria que distinguir entre cuestiones de fe y cuestiones de hecho. Mientras para las primeras hay que buscar un Juez infalible (Escrituras u hombre dotado por Dios), para el resto no puede obtenerse certeza absoluta sino probable ${ }^{71}$, y sólo se precisan dos condiciones para tomar parte en la controversia e intentar aproximarse

${ }^{\$ 6}$ Cfr. Nuevos Ensayos, IV, 7, 19 (GP IV, 405; Echeverria, 506). Cfr. también cartas a Bayle, 1702 (GP III, 69); Molanus, 22 de junio de 1700 (GP VII, 551); Des Bosses, 11 de julio de 1706 (GP II, 311); a Bourguet, 5 de agosto de 1715 (GP III, 581); a la princesa Sofia, 6 de febrero de 1706 (GP VII, 566); a Des Bosses, 20 de septiembre de 1706 (GP II, 317).

${ }^{57}$ Von der Glücksetigkeit, Guhrauer, Deatsche Sctriften, 425; Olaso, 399.

* Cfr. De l'usage de la Meditation, GP VII, 79.

* En este sentido, en uno de sus proyectos para una Ciencia general presenta Leibniz, como uno de los requisitos del arte de razonar, accptar como verdadero únicamente lo que esté fuera de duda, para lo que recomienda ejercitarse en sostener lo contrario de lo que uno piensa, con el fin de evitar los prejuicios, esto es, colocarnos en el lugar del otro procurando defender aquellos argumentos con los que quizá no coincidimos (cfr. De la sagesse, GP VII, 82).

${ }_{73}$ Pues deben de tener en cuenta que otros, tan persuadidos como ellos, tienen el mismo derecho para defender sus concepciones e incluso para propagarlas, si las creen importantes. Hay que exceptuar las maneras de pensar que enseñan crimenes, las cuales no deben ser toleradas $y$ hay derecho a ahogarlas por medios rigurosos, aun cuando fuese verdad que el que las defiende no puede dejar de defenderlas: exactamente igual que se tiene derecho a destruir una bestia venenosa, por inocente que sea. Pero yo me refiero a aplastar la secta, y no a los hombres, puesto que se les puede impedir causar daños y dogmatizar", Nuevos Ensayos, IV, 16, 4; Echeverría, 560.

"Cfr. El juez de las controversias o la balanza de la razón, \$§ 33-36 (A VI, 1, 549). 
a la solución: buena voluntad y capacidad de razonar ${ }^{22}$. Veamos una muestra del empleo de la razón en controversias religiosas: «Según afirma Jurieu [en el cap. 17 de su apologie de la reforme contre $M$. Maimburg], los Jesuitas dicen que el hombre puede hacer sin la gracia los mismo buenos actos, a partir de su sustancia y grados, que haria con la gracia, pero que sin la gracia no son saludables en absoluto. Pero esto vuelve injusto a un Dios que trata desigualmente a aquellos que hacen la misma cosa, condenando a los que hacen el bien por sus propias fuerzas, y no salvando más que a los que hacen las mismas cosas con su ayuda ${ }^{73}$. Sobre esta base, los esfuerzos leibnizianos para superar las controversias religiosas y conseguir la reunificación de las iglesias (primero protestantes y luego cristianas, pero con una clara intención cosmopolita) consistían en colocar por encima de las creencias de primer orden (constituidas por las distintas religiones) una metacreencia: la tolerancia fundamentada en la capacidad racional humana, es decir, en la potencialidad crítica del hombre racional que es capaz de distanciarse de sus propias creencias, para estimarlas y juzgarlas de acuerdo con algún criterio independiente o relativamente independiente de ellas ${ }^{74}$.

Ahora bien, cuando no se trata de controversias religiosas, sino seculares «que no tocan el fundamento de la fe, no es necesaria una absoluta infalibilidad, sino certeza moral o infalibilidad práctica, tal y como afirma en su texto $E l$ juez de las controversias. Y las controversias teóricas no son propias de este lugar sino en cuanto pueden modificar la práctica, como por ejemplo la cuestión teótica de la circulación de la sangre puede cambiar la praxis médica. Estas controversias prácticas -continúa Leibniz - o las resuelve cada uno para sí mismo, o se necesita el consenso de la sociedad. Así, en el mundo actual cada uno decide, sin ningún permiso de la República, la cuestión práctica sobre qué género de vida quiere para sí y para sus hijos, si le es útil viajar y cosas por el estilo; y en estos casos es la razón el juez de la decisión. Mientras que otros asuntos han de ser sancionados por la autoridad y la decisión de la sociedad; por ejemplo, todo lo relacionado con la actividad pública, la guerra, la paz, los pactos, la fuerza pública, la administración, la venta inmobiliaria (en determinados lugares), la emigración (en determinados lugares), y otras del mismo género» ${ }^{75}$. Cuando en las causas, dirá, los jueces son determinados individuos o ciertos colectivos, hay que tener en cuenta que pueden estar some-

${ }^{72}$ Cfr. Sobre las controversias (A IV, 3, 204-212). Dice textualmente: «Si todos los hombres tuvieran la misma buena voluntad que tengo yo, y si todos aquellos que tienen esta buena voluntad tuvieran además la fuerza penetrante de vuestra Alteza, no tendriamos necesidad de método en las disputas... la capacidad de razonar ha sido equilibradamente repartida entre todos los hombres, de manera que lo unico que les falta es la voluntad de servirse de ella.»

"De gratia sententige ex Jurieu excerptae (1686), VE N. 381, p. 1781.

${ }^{74}$ En este sentido, afirma Toni Doménech, usi no tuviéramos creencias de segundo orden, ni se nos ocurriria la posibilidad de mejorar nuestra información sobre el mundo»; cfr. De la ética a la politica, Crítica, Barcelona, 1989, p. 20.

is El juez de las controversias, $\$$ 37-39, A VI, 1, 549. 
tidos a las pasiones (se dejan llevar por las emociones, el amor, el odio, la envidia o la cólera) ${ }^{76}$. Ni siquiera el juicio de la mayoría está a resguardo de ellas ${ }^{77} y$, para Lcibniz, no hay mucha difcrencia entre decidir en la confusión de las pasiones o echar las cosas a suertes ${ }^{78}$, por lo tanto, dirá, «vistas así las cosas, siendo el hombre proclive a las pasiones, y siendo la suerte irracional, habrá que buscar una Razón, pero que esté libre de pasiones. Tal razón no se encuentra en ningún hombre particular, sino que es la Recta Razón misma considerada en abstracton" ${ }^{79}$.

Y al servicio de este ideal, a la búsqueda de la recta razón en las controversias, pondrá Leibniz toda su ciencia y su actividad política a lo largo de su vida (no sólo cifrada en la reunificación de las Iglesias, sino también en la organización federal de Estados alemanes, en la fundación de Academias o en su mediación en la firma de tratados de paz - como he desarrollado en otros de mis trabajos-). Será precisamente en este marco en el que hay que incluir su ambicioso proyecto de elaboración de una lengua o Característica universal, cuya misión última sería acabar con los errores de razonamiento (como se acaba con los errores de cálculo); esta lengua universal, inspirada en parte en los ideogramas chinos y egipcios, serviría de base a una filosofía racional, donde una especie de alfabeto de pensamientos sometidos a la pura combinatoria se convertiría en el «Juez de las controversias», como escribe al duque J. Federico en $1679^{80}$. Se trataría de una escritura universal que

${ }^{*}$ Por eso, un buen político que quiera, por ejemplo, elaborar un programa realista para conseguir la paz perpetua ha de contar con las pasiones de los gobernantes e idear la manera de servirse de ellas para sus propios fines, tal y como escribe Leibniz al Abbé de Saint-Pierre (4 de abril de 1715): «No sería vano para este propósito que el mayor Banco de Europa estuviera en manos del Consejo General y que todos los príncipes tuvieran (cada uno proporcionalmente) millones depositados en dicho Banco, los cuales estarían allí tan seguros como en sus cofres y les proporcionarian incluso intereses. Así su capital no permanecería improductivo y serviría a su vez como una especie de caución burguesa”, en Voprosy filosofii, 18 (1964), pp. 121-124; en el mismo sentido se había expresado en una carta a Grimarest el 4 de junio de 1712; sobre este tema cfr. mi artículo "Los "prolegómenos" sobre la paz perpetua», citado en nota 6 .

"Cfr. ibid, \$\$ 45-47: ude todos los jueces de controversias comúnmente conocidos, el mejor es la mayoria de votos, pues habrá que obedecer a la voluntad de los más en la medida en que en caso de duda la mayor parte deba ser tomada por el todo, ya que es por naturaleza la más próxima al todo... Pero no puede perderse de vista que también este juez de las controversias está sometido a las mismas dificultades que el simple hombre (aunque no tan fácil ni tan frecuentemente), es decir, a las pasiones, pues anda es más voluble que una multitudss.

"s aCuando se trata de conseguir un bien, por ejemplo, qué duque elegir en Venecia o qué rey en Polonia, es más tolerable depender de la suerte, pues a nadie se perjudica si este rey no es elegido. Pero cuando se busca evitar un daño, por ejemplo, si se trata de la vida o fortuna de un hombre o de la solución de conflictos, thabrâ algo más improcedente que decidirlo a suertes, aunque sepamos que algunos jueces asi lo hicieron? (...) Y esperar en estos casos una asistencia extraordinaria de Dios es casi una impiedad, pues Dios nos ha dado la razón para que la usemos y no le tentemos con lances inciertos» (ibid, $\$ \$ 48-51$ ).

i3 libid., \$52.

* «He empezado a meditar ciertas consideraciones completamente nuevas, para reducir todos los razonamientos humanos a una especie de cálculo, que serviria para descubrir la verdad... 
cada uno entendería en su propia lengua ${ }^{81}, 0$, como escribe a Galloys en 1677: «Una lengua racional cuyo menor efecto sería la universalidad y la comunicación de diferentes naciones» ${ }^{82}$.

Queda, pues, clara la intención cosmopolita de este proyecto de invención de una lengua universal que ya había sido acariciado por Descartes -como nos recuerda Miguel Sánchez-Mazas en uno de sus desgraciadamente últimos trabajos- ${ }^{83}$. Un gran número de autores se han ocupado de demostrar que el objetivo de Leibniz, por las mismas limitaciones internas de los formalismos, es inalcanzable, aunque subrayan la importancia lógico-matemática de nuestro autor ${ }^{84}$. Ahora bien, quizá no debamos perder de vista la razonabilidad y el sentido común que se dibujan a la base de ese proyecto que persigue el diálogo entre culturas no para caer en el relativismo, sino para superarlo, haciendo del pluralismo la mejor arma contra los absolutismos de todo signo ${ }^{85}$. Además,

Esta especie de cálculo general proporcionaría al mismo tiempo una especie de escritura universal que tendría las ventajas de las de los chinos, porque cada cual la entendería en su lengua, pero que sobrepasaria infinitamente a la de los chinos porque cabría aprenderla en varias semanas, ya que sus caracteres estarían ligados según el orden y la conexión de las cosas... Esta misma escritura sería una especie de Algebra general y nos daría el medio para razonar calculando, de modo que en lugar de disputar podriamos decir: contemos. Y sucedería que los errores de razonamiento no serían sino errores de cálculo que se descubririan mediante pruebas, como en la aritmética. Los hombres encontrarían en ella un juez de sus controversias verdaderamente infalible» (GP VII, 25-26; trad de J. Echeverría, Leibniz, pp. 119-120).

${ }^{81}$ Cfr. GP VII, 25.

*2. GP VII, 21. En la puesta en práctica de este método «la tarea de juzgar debe ser encomendada a la República, y la de inventar a sus partes o a aquellos a quienes la Rcpública cncarga la asistencia a las partes. En las causas que atañen a la República misma los particulares son las partes, y el todo es el juez, empleando la forma rigurosa que excluye todo fraude. Todo esto podria organizarse primero en una sociedad universal de sabios, y poco a poco, con el paso del tiempo, se iría extendiendo cómodamente al resto de los ciudadanos", El juez de las controversias, $\$ 70(\mathrm{~A}$ VI, 1,551$)$.

* Cfr. «Calculemos... Matemáticas y libertad», en Calculemos.. Matemáticas y liberiad (Homenaje a Miguel Sánchez-Mazas), J. Echeverria, J. de Lorenzo y L. Peña (editores), Trotta, Madrid, 1996, pp. 15-16: «Leibniz abria en su Prefacio a la ciencia general, escrito probablementc cn 1677, un debate que aún hoy sigue palpitante y abierto, evocando la posibilidad de esa nueva lengua, de base racional y de alcance universal, que con distintas formas iria tomando cuerpo cn su espíritu, principalmente bajo el nombre de Caracteristica taniversal. Sin embargo, el embrión de esa idea y de la grandiosa concepción que le siguió se encontraha ya desde hacía medio siglo -iquién lo hubiera dicho! - en la obra de Descartes - cuyas perspectivas logicas y metodológicas Leibniz tan despiadadamente criticó- y concretamente en una famosa carta de Descartes a Mersennc, escrita en 1629, es decir, diecisiete años antes del nacimiento de Leibniz, como éste implícitamente reconoció, pues entre sus escritos aparece un importante fragmento de esa carta, copiado por un secretario y encuadrado por un comienzo y un final, de puño y letra del propio Leibniz»; cfr. Couturat, Opuscules et fragments inédits de Leibniz, pp. $27-28$.

${ }^{84} \mathrm{Cft}$, ibid., pp. 16-17. Son citados Gödel, Church, Löwenheim, Skolem y Klecne. Las limitaciones internas de los formalismor es precisamente el título que el filósofo belga Jean Ladrière dio a su libro publicado en 1957.

${ }^{85}$ En un sentido muy similar afirmaba hace unos años U. Moulines en Pluralidad y recursion, Alianza, Madrid, 1991, p. 30: «La actitud filosófica que se propone en este libro no es relativista, 
Leibniz no se cansó de repetir que en las esferas en que no obtengamos certezas, no hemos de desechar las probabilidades, que nos hacen progresar aunque sea imperceptiblemente en la filosofia práctica, a cuyo servicio está nuestra racionalidad teórica. El modelo jurídico le sirvió en muchas ocasiones de paradigma para constituir esta lógica de lo verosímil a la que llama «balanza de la razón» ${ }^{86}$, y cuyo principal objetivo es el constante perfeccionamiento y el «acercamiento al punto de vista corrector ${ }^{87}$, que en cuestiones prácticas pasa por la consideración respetuosa y reflexiva de «la perspectiva del punto de vista del otro», siguiendo el norte de la justicia y la tolerancia, peldaños para ascender en la persecución de un mayor bien para el género humano.

\section{DESENLACE}

En resumen, podemos afirmar que la filosofía de Leibniz, particularmente en su vertiente práctica, es un ars disputandi, de ahí la importancia que tienen su correspondencia y la redacción de diálogos como vehículo de expresión. El valor de las discusiones científicas y de las controversias reside en su capacidad para poner de manifiesto que en cada perspectiva hay una parte de verdad, eludiendo así el peligro de dogmatismos y absolutismos, pero huyendo al mismo tiempo del relativismo de la mano de la creencia en una paulatina aproximación racional a la verdad. Pero, a su vez, la teoría alcanza su realización en su proyección práctica, donde las verdades se traducen en bienes que cooperan a la consecución de la justicia y la felicidad de la pluralidad de los seres humanos, obteniendo de esa proyección práctica la piedra de toque de la verdad.

Para terminar volviendo a los planteamientos iniciales de este trabajo, quisiera apuntar, por lo tanto, que las conclusiones generales que desde mi punto de vista se deducen de la reconstrucción de la filosofía práctica leibniziana que aquí presento vienen a incidir de un modo altamente fecundo y provechoso en nuestra comprensión de la Modernidad, resultándonos extremadamente útiles para revisar los conceptos centrales del programa ético moderno que hemos heredado (me refiero a tópicos tales como razón, autonomía, libertad, igualdad, justicia, tolerancia...), así como en la construcción de nuevos cauces de creatividad práctica.

En cualquier caso, nuestra apuesta ha de ser una apuesta por la complejidad, única fuente de enriquecimiento de lo humano. Complejidad de perspectivas, complejidad de ideas, complejidad de debates, complejidad de soluciones.

En esta época de bebidas light y cigarrillos light, hay que defenderse contra la tentación de hacer una filosofía light, donde la fragmentación se confunda con la cortedad de miras.

pero sí pluralista y, en consecuencia, antiabsolutista, es decir, contraria a la idea de un único sistema de creencias y métodos válido en el conocimicnto humano.»

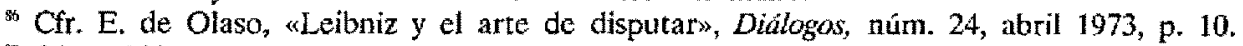

si Olaso, 389. 